\title{
Experimental investigation of Robotic Surface Finishing Using Abrasive Disc
}

\author{
S. N. Padmanabhan, Z. Halil, Y. Sun, T. T. Vu, S. H. Yeo, and A. Wee
}

\begin{abstract}
This study is based on the optimization of process parameters in abrasive robotic finishing process. The effect of certain process parameters on the surface finish of the abraded surface is to be studied using Design of Experiments (DOE) methodology. The finishing or polishing operation is vital in any manufacturing processes. Methods have evolved from hand finishing operations to automatic finishing using CNC machines used currently. This research pertains to the next level of finishing with the usage of a robot. A set of influential parameters that are critical in a grinding operation was chosen as the input parameters. The influence of the selected parameters on the output response, which is the surface roughness, is to be analyzed and investigated. The material removal would be brought about with the help of abrasives in the form of discs. Coated abrasives and non-woven type surface conditioning abrasives in the form of discs were chosen as the cutting tools. Minitab statistical software was used in determining the factors with significant impact on the output response and for optimizing the parameters to obtain the best surface roughness. The expected outcome of this research work will be in the form of experimentally verifying the set of optimized parameters in abrasive robotic finishing operation.
\end{abstract}

Index Terms-Robotic finishing, abrasive disc, design of experiment.

\section{INTRODUCTION}

In a highly competitive market today, finishing operation is an eminent process in any manufacturing industry, whereby more emphasis has been given on the aspects of fine tolerance, high accuracy and good surface finish to clear the vigilant quality standards. The final quality of the finished product is determined by the finishing/grinding process, which accounts up to around $20-40 \%$ of the overall manufacturing costs [1]. With the end product quality achieved by means of fine material removal, finishing operation needs high energy inputs per unit volume of material removal compared to other processes such as milling, grinding and turning.

Manuscript received November 7, 2016; revised April 5, 2017. This work was conducted within the Rolls-Royce@NTU Corporate Laboratory with support from the National Research Foundation (NRF) Singapore under the Corp Lab@University Scheme.

S. N. Padmanabhan was with the School of Mechanical and Aerospace Engineering, Nanyang Technological University, Singapore.

Z. Halil, Y. Sun, and T. T. Vu is with Rolls-Royce @ NTU Corporate Lab, School of Mechanical and Aerospace Engineering, Nanyang Technological University, Singapore (e-mail: ZULQARNAIN@ntu.edu.sg, YJSUN@ntu.edu.sg).

S. H. Yeo is with the School of Mechanical and Aerospace Engineering, Nanyang Technological University, Singapore (e-mail: MSHYEO@ntu.edu.sg).

A. Wee is with the Advanced Technology Center-Manufacturing Technology, Rolls-Royce, Singapore (e-mail Arthur.Wee@Rolls-Royce.com).
Finishing operations can be done either manually or be automated. Manual grinding is a laborious task which is time consuming and extracts a high amount of labour force. Another major concern lies on the fact that manual grinding operations are dangerous and exploits the health of the worker. Subsequently, Computer Numerical Control (CNC) machines have taken over the responsibility of delivering very fine surface finishes as per the industry needs. Recently, many studies have been carried out in the direction of using industrial robots for the final grinding process, which offers a higher advantage considering their programmability, adaptability and flexibility [2]. The robots can also aid in carrying out the preceding and subsequent handling processes.

Compared to CNC work centers, the control of robots is challenging essentially due to the lack of rigidity and stiffness. One of the major concerns with the usage of industrial robots was low material removal rate, due to the low stiffness [1]. In robotic systems, the machining process is actually accomplished with the use of tools being made to touch the work pieces with a specific amount of force. The machining forces are subjected to variations due to variation of metal engaged in the cutting process. Recent literature works on the force control strategies adopted on robotic systems has yielded good results to improve the material removal rates. The force sensors are designed in such a manner that they are not only capable of controlling the cutting forces but can also control the speed of the robot. This is done by sensing the change in the cutting conditions and dynamically adjusting the robot's speed [3].

Generally, the advantage of finishing is to reduce or eliminate the surface defects like micro-cracks, tensile residual stress, voids and burn outs that might damage the surface of the work specimen in conventional grinding [4]. Tools for finishing vary by a large margin including belts, discs, wheels, sheets, pads, cones etc. If abrasive discs are taken into consideration, they are internally subdivided into different types based on the abrasive type namely bonded, coated, non-woven and filament. Bonded abrasives are less compliant and the filament type makes multiple contacts with the specimen. The non-woven types have intricate surfaces. Abrasive polishing, an example of surface finishing, uses abrasive grains which are generally of the size less than 1 micron. It is generally accepted that the final surface roughness depends on the size of the abrasive particles used [5].

This study aims to identifying the effect of process parameters for polishing a given surface, from which the process parameters are optimized on basis of achieving minimum surface roughness $\left(R_{a}\right.$ and $\left.R_{z}\right)$. The next section 
illustrates the methodology on the usage of industrial robots for machining operations, abrasive surface finishing processes, properties and selection of abrasive tools, design of experiments (DOE). The third section presents and discussed the collected material removal results. The last section concludes this study.

\section{Methodology}

\section{A. Design of Experimental Method}

Design of Experiment (DOE) is a handy statistical technique that is highly effective in studying the effect of multiple factors such as parameters, variables, ingredients on the final performance or outcome of a process. It is also used to optimize the process and product designs. The primary step to perform a DOE lies on the collection of data pertaining to the process on which the technique is going to be applied. In our case, abrasive finishing on robotic application is the process and several factors that might affect the final output of achieving minimum surface roughness $\left(R_{a}\right.$ and $\left.R_{z}\right)$ are studied. In particular, four factors that are to be varied and investigated are selected which might have high priority in influencing the surface roughness $\left(R_{a}\right)$; they are 1) spindle speed, 2) tool feed rate, 3) type of tool and 4) workpiece geometry. Out of the above four chosen factors, it is to be noted that two factors (spindle speed and tool feed rate) are real machining parameters that will have high influence on the $R_{a}$. The other two factors (tool type and workpiece geometry) are taken into consideration keeping in mind the other scope of this study (ie) a comparative study on two different types of tools on the $R_{a}$.

There are different design methodologies that can be adopted in performing DOE. Each methodology has its own pros and cons which vary depending on the experimentation point of view. Full factorial design, fractional factorial design, Plackett Burman design are some effective methodologies adopted in performing a DOE. Amongst them, the full factorial design is the most efficient design in DOE as it provides the complete data required for the analysis. Selection of level/order is another important step in DOE. It is generally preferred to have either 2 or 3 levels when it comes to full factorial designs because as the order increases, the number of experiments to be conducted increases as well. The selected four factors are be tested at two levels using full factorial design consisting of 24 (16) runs. The factors and its corresponding low and high factor levels are tabulated in Table I.

TABLE I: LEVELS OF FACTORS

\begin{tabular}{lll}
\hline \hline Factors & Low Level & High Level \\
\hline Spindle Speed (rpm) & 7500 & 10000 \\
\hline Feed Rate (mm/min) & 300 & 600 \\
\hline Type of Tool & $\begin{array}{l}\text { 2" Roloc Trizact } \\
\text { Grade A45 }\end{array}$ & $\begin{array}{l}\text { 2" Roloc Non-Woven } \\
\text { Grade ACRS }\end{array}$ \\
\hline $\begin{array}{l}\text { Workpiece } \\
\text { Geometry }\end{array}$ & Concave & Convex \\
\hline \hline
\end{tabular}

\section{B. Experimental Setup}

The experiments were conducted with the ABB robot IRB
6640. An ATI force sensor was attached at the end effector of the robot, onto which a spindle was then attached. The tools under study were then attached onto the spindle. On the other hand, the workpieces to be machined on were secured into place by fixtures onto a designated T-slot table.

The tools used were of 2 inch 3M Trizact Grade A45 and $3 \mathrm{M}$ Non-Woven disks attached onto $3 \mathrm{M}$ hard rubber backing pads, shown in Fig. 1. The workpieces were made of aluminium 6061-T651 with the surface geometry of concave and convex types with radius of curvature of $120^{\circ}$. The surfaces of the workpieces were ball-milled using a diameter $12 \mathrm{~mm}$ ball cutter, thus having an initial roughness of $3 \mu \mathrm{m}$. The angle of the tool was kept at $10^{\circ}$ to the surface of the workpiece during machining.

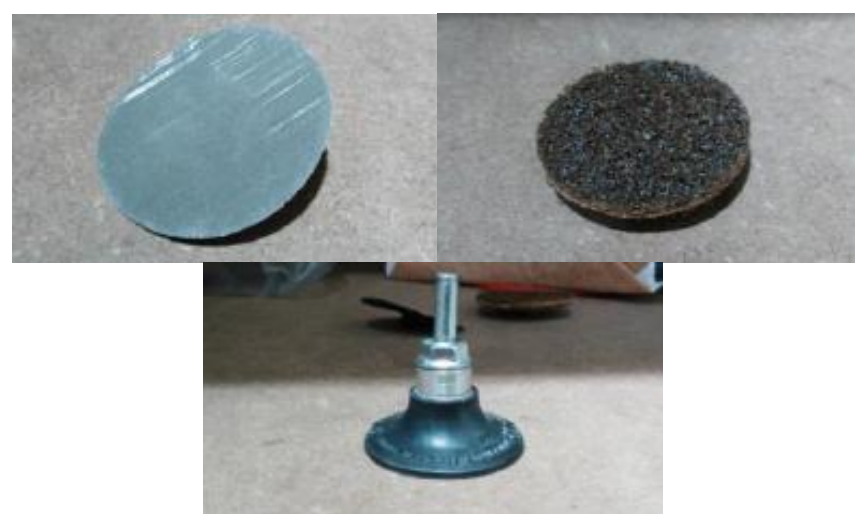

Fig. 1. From left, 3M Trizact Grade A45, 3M Non-Woven Grade ACRS, hard rubber backing pad.

ABB Robot Studio was used as the software for programming the robot movements in $3 \mathrm{D}$ space and controlling the speed of rotation of the tools. A force control method of material removal was employed for the tests, ensuring consistent amount of force being exerted by the tool on the workpiece surface. The values of force exerted were read by the ATI force sensor, which was then displayed on the ABB Test Signal Viewer. A constant force of $50 \mathrm{~N}$ was employed for all the test runs in this paper.

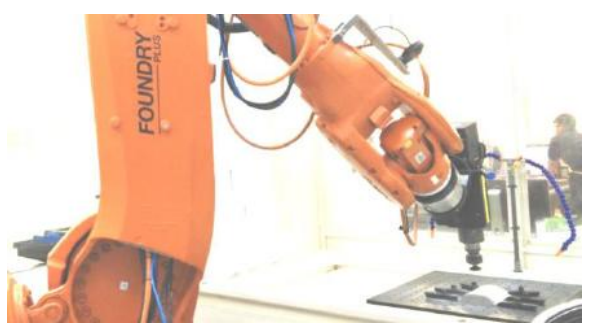

Fig. 2. Experimental Setup.

The surface roughness parameters $R_{a}$ and $R_{z}$ of the surface was measured using Mitutoyo Surftest Extreme SVM3000CNC with a S-3000 $2 \mu \mathrm{m}$ tip radius probe.

\section{RESUlTS AND DISCUSSION}

\section{A. Key Parameters and Their Relationships}

In this study, the parameters that have an impact on the surface roughness and optimization of the parameters to achieve the best surface roughness were investigated and 
determined respectively. Both of these investigations were being done using Minitab, a statistical software suitable for DOE studies.
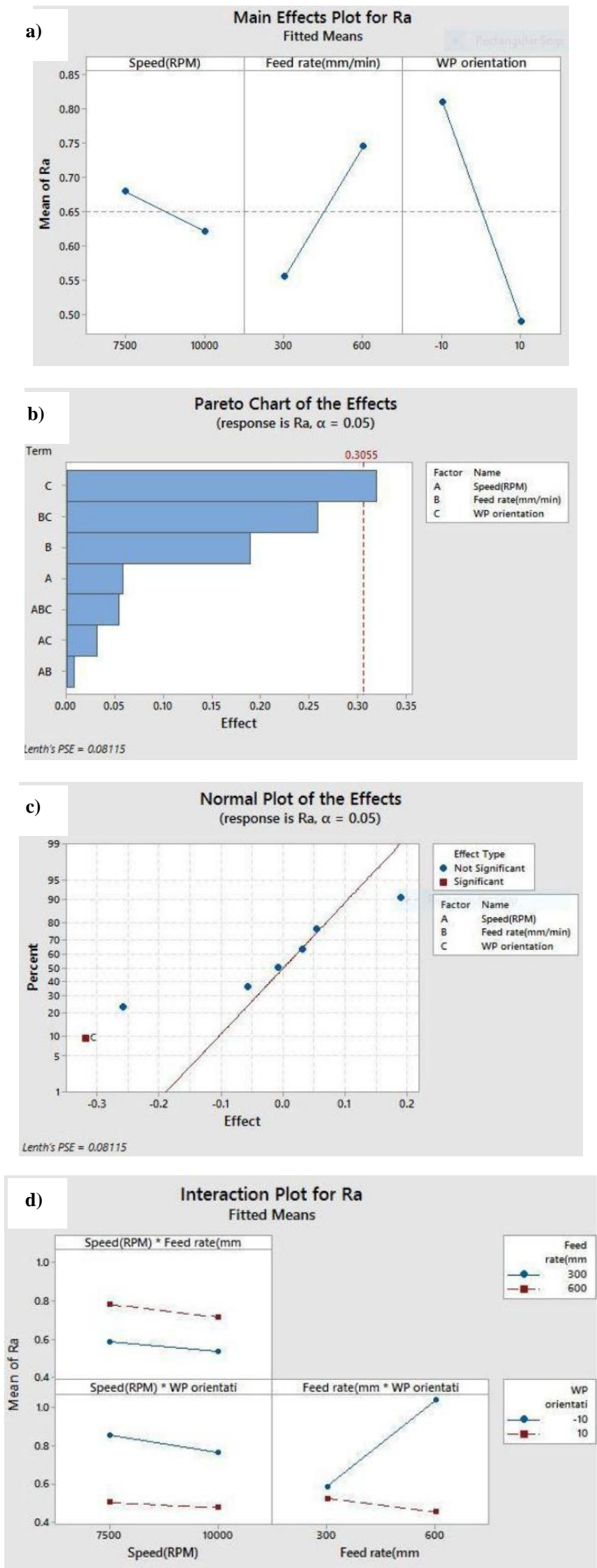

Fig. 3. Effects of using a non-woven tool on the $R_{a}$ a) the Main Effects Plot for $R_{a} ; \mathrm{b}$ ) the Pareto Chart of the effects; c) the Normal Plot for the effects; d) the Interaction Plot for the $R_{a}$.

To determine the impact of the parameters (feed rate, spindle speed, tool type, workpiece geometry) on the surface roughness $\left(R_{a}\right.$ and $\left.R_{z}\right)$, the main effects plots, Pareto charts, normal plots and interaction plots from the results of the full factorial DOE were generated. Examples of these plots are shown in Fig. 3 for studying the effects on the parameter $R_{a}$ by using a non-woven tool for machining, where a low level value for workpiece geometry corresponds to a concave surface and vice versa.

From Fig. 3a, it can be seen that by increasing the spindle speed, feed rate and the workpiece geometry level, a decrease, increase and decrease in the $R_{a}$ correspondingly to each change were measured. Furthermore, from Fig $3 b$ and $3 c$, the significant factor affecting the surface roughness is the workpiece geometry. Finally, in Fig. 3d, it can be seen that the interaction between feed rate and workpiece geometry shows significance due to their intersection. The overall outputs of the charts are summarized in Table II, showing the changes in the surface roughness with the change in each parameter level.

TABLE II: COMPARISON OF RESULTS BETWEEN THE NON-WOVEN AND TRIZACT TOOLS

\begin{tabular}{lllll}
\hline \hline & \multicolumn{2}{c}{$\mathbf{R}_{\mathbf{a}}$} & \multicolumn{2}{c}{$\mathbf{R}_{\mathbf{z}}$} \\
& $\mathrm{NW}$ & Trizact & NW & Trizact \\
\hline $\begin{array}{l}\text { Increasing Feed } \\
\text { Rate }\end{array}$ & Increases & Increases & Increases & Increases \\
\hline $\begin{array}{l}\text { Increasing } \\
\text { Speed }\end{array}$ & Decreases & Decreases & Decreases & Increases \\
\hline $\begin{array}{l}\text { Using Concave } \\
\text { Workpiece }\end{array}$ & Increases & Increases & Increases & Decreases \\
\hline $\begin{array}{l}\text { Using Convex } \\
\text { Workpiece }\end{array}$ & Decreases & Decreases & Decreases & Increases \\
\hline \hline
\end{tabular}

It can be seen in Table II that the workpiece geometry and spindle speed does not contribute any significance to the response variable $R_{z}$ since no trends can be seen in changing the aforementioned parameters. On the other hand, the significant factors for the tools based on all of the generated plots are summarized in Table III.

TABLE III: SIGNIFICANT FACTORS FOR THE TOOLS

\begin{tabular}{|c|c|c|}
\hline Resultants & $\mathbf{R}_{\mathbf{a}}$ & $\mathbf{R}_{\mathbf{z}}$ \\
\hline Non-Woven & $\begin{array}{l}\text { - WP geometry } \\
\text { - Interaction between } \\
\text { feed rate and WP } \\
\text { geometry }\end{array}$ & $\begin{array}{l}\text { - Interaction between feed } \\
\text { rate and WP geometry }\end{array}$ \\
\hline Trizact & $\begin{array}{l}\text { - No significant } \\
\text { factors } \\
\text { - They have p values } \\
\text { close to } 0.05\end{array}$ & $\begin{array}{l}\text { - Interaction between feed } \\
\text { rate and WP geometry } \\
\text { - Interaction between feed } \\
\text { rate and spindle speed } \\
\text { - Interaction between } \\
\text { spindle speed and WP } \\
\text { geometry }\end{array}$ \\
\hline
\end{tabular}

\section{B. Optimization for Minimum Surface Roughness}

Using the same results obtained from the full factorial DOE analysis being fed as input data into the Minitab software, multiple regression optimization technique was then employed to obtain optimized parameters for the best $\mathrm{R}_{\mathrm{a}}$ and $R_{z}$ values. The software will develop a fitting model automatically when the necessary data is provided. The 2 fitting models for the output parameters $R_{a}$ and $R_{z}$ are as follows: 


$$
\begin{gathered}
R_{a}=0.3305+0.000532 X_{2}+0.0807 X_{3}+0.01051 X_{4}- \\
0.000049 X_{2} X_{4}-0.00448 X_{3} X_{4} \\
R_{Z}=1.39+0.00557 X_{2}
\end{gathered}
$$

where $X_{1}$ refers to the spindle speed (rpm), $X_{2}$ refers to the feed rate $(\mathrm{mm} / \mathrm{min}), X_{3}$ refers to the tool type and $X_{4}$ refers to the workpiece geometry. $X_{3}$ level of -1 and +1 corresponds to non-woven and Trizact tools respectively and $\mathrm{X}_{4}$ levels of -10 and +10 refer to concave and convex geometry respectively.

Pertaining to the fitting models, the input factors feed rate, workpiece geometry, tool type and their interactions have been identified as significant factors for achieving a minimum roughness $R_{a}$. These results correlate with the results obtained in Table III. The spindle speed does not have any effect with the response variable, thus, explaining the absence of $X_{1}$ within the fitting models.

To optimize $R_{a}$, a low level feed rate and Trizact tool are to be used on a concave surface. Another alternative solution would be using a low feed rate and non-woven tool on a convex surface. On the other hand, to optimize $R_{z}$, a low level feed rate is to be used.

\section{CONCLUSION}

This project aimed in the study of abrasive polishing process with robotic application. Two types of abrasive tools were selected to check their performance in achieving the task. The experiments to be performed were designed using full factorial method in Minitab software. Two level designs were followed with all factors being assigned a high and low value. Two real machining parameters and two supporting parameters for comparison were chosen as the input variables. The output response was roughness measurement $\left(R_{a}\right.$ and $\left.R_{z}\right)$.

The output responses were thus summarized in Table II and III, where spindle speed does not show any significant effects. Also, different combinations of significant factors were seen between the output responses. These differences are also shown through the fitting model equations 1 and 2. Finally, through optimization, the optimized process parameters determined were $7500 \mathrm{rpm}$ and $300 \mathrm{~mm} / \mathrm{min}$ for spindle speed and feed rate, respectively.

Some areas of improvement to increase the accuracy of the results are to increase the number of levels from two to three at the factorial design and the number of replicates for each trial in DOE for detailed analysis.

\section{REFERENCES}

[1] J. Pandremenos, C. Doukas, P. Stavropoulos, and G. Chryssolouris, "Machining with robots: A critical review," in Proc. DET2011 7th International Conference on Digital Enterprise Technology, Greece, 2011, pp. 614-621.

[2] R. T. Coelho, H. H. T. Rodella, V. F. Martins, and J. R. Barba, "An investigation into the use of industrial robots for machining soft and low density materials with HSM technique," Journal of the Brazilian Society of Mechanical Sciences and Engineering, vol. 33, pp. 343-350, 2011.

[3] F. Domroes, C. Krewet, and B. Kuhlenkoetter, "Application and analysis of force control strategies to deburring and grinding," Modern Mechanical Engineering, vol. 3 no. 2A, pp. 11-18, 2013.

[4] R. L. Aghan and L. E. Samuels, "Mechanisms of abrasive polishing," Wear, vol. 16, pp. 293-301, 1970.

[5] Y. Xie and B. Bhushan, "Effects of particle size, polishing pad and contact pressure in free abrasive polishing," Wear, vol. 200, pp. 281-295, 1996.

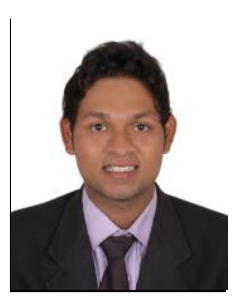

Shankara Narayanan Padmanabhan is a post graduate (Master`s degree) in Manufacturing Systems and Engineering from Nanyang Technological University, Singapore (Class of 2016). Shankar earlier graduated with a bachelor's degree in Mechanical Engineering from Anna University, Tamil Nadu, India in 2015 .

$\mathrm{He}$ is presently working in Singapore and has research experience in the form of his Master Thesis which was done with the Rolls-Royce@ NTU Corp Lab, Singapore. His area of interests are advanced manufacturing technologies and automotive engineering.

Mr. Shankar is an active member of SAE International - (Society of Automotive Engineers) and IMechE - (Institution of Mechanical Engineers). He has been awarded with the Student of the year award from SAEINDIA in 2015 in appreciation of his contribution to the society during his bachelor degree. 